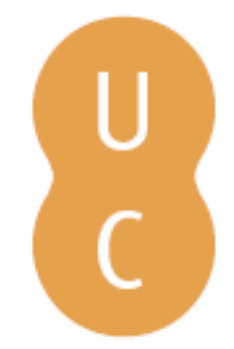

\title{
nombalina
}

\section{Caracterização geofísica das aluviões de Vila Nova, Penacova: avaliação de condicionantes estruturais e da heterogeneidade hidrogeológica}

Autor(es): $\quad$ Veiga, N. M. S. Alte da; Azevedo, J. M.

Publicado por: Imprensa da Universidade de Coimbra

URL

persistente: URI:http://hdl.handle.net/10316.2/31459

DOI: $\quad$ DOI:http://dx.doi.org/10.14195/978-989-26-0531-9_27

Accessed : $\quad$ 26-Apr-2023 12:52:39

A navegação consulta e descarregamento dos títulos inseridos nas Bibliotecas Digitais UC Digitalis, UC Pombalina e UC Impactum, pressupõem a aceitação plena e sem reservas dos Termos e Condições de Uso destas Bibliotecas Digitais, disponíveis em https://digitalis.uc.pt/pt-pt/termos.

Conforme exposto nos referidos Termos e Condições de Uso, o descarregamento de títulos de acesso restrito requer uma licença válida de autorização devendo o utilizador aceder ao(s) documento(s) a partir de um endereço de IP da instituição detentora da supramencionada licença.

Ao utilizador é apenas permitido o descarregamento para uso pessoal, pelo que o emprego do(s) título(s) descarregado(s) para outro fim, designadamente comercial, carece de autorização do respetivo autor ou editor da obra.

Na medida em que todas as obras da UC Digitalis se encontram protegidas pelo Código do Direito de Autor e Direitos Conexos e demais legislação aplicável, toda a cópia, parcial ou total, deste documento, nos casos em que é legalmente admitida, deverá conter ou fazer-se acompanhar por este aviso.

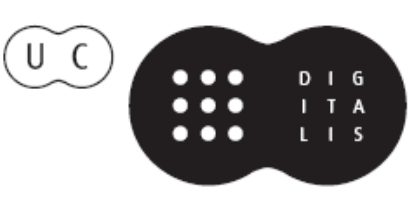





\title{
CARACTERIZAÇÃO GEOFÍSICA DAS ALUVIÓES DE VILA NOVA, PENACOVA - AVÁLIAÇÁO DE CONDICIONANTES ESTRUTURAIS E DA HETEROGENEIDADE HIDROGEOLÓGICA
}

\author{
GEOPHYSICAL CHARACTERIZATION OF THE ALLUVIAL DEPOSITS \\ OF VILA NOVA, PENACOVA - EVALUATION OF STRUCTURAL \\ CONSTRAINTS AND THE HYDROGEOLOGICAL HETEROGENEITY
}

Resumo - O depósito aluvionar de Vila Nova, Penacova, forma uma mancha alongada com uma extensão ligeiramente superior a $1 \mathrm{~km}$, situada na margem esquerda do rio Mondego, na região de Penacova. Esta região é atravessada pelo sinclinal do Buçaco-Penedo de Góis, com orientação NW-SE, constituído por séries do Ordovícico-Silúrico. O depósito assenta sobre as séries paleozoicas do núcleo do sinclinal. Nas formaçóes aluvionares evolui um aquífero não-confinado, limitado a W pelo Rio Mondego, e inferiormente e a E pelas formaçóes paleozoicas com reduzida condutividade hidráulica. Sobre este depósito foram efetuados levantamentos com métodos geofísicos que conduziram à obtenção de secçôes bidimensionais de resistividade eléctrica, as quais permitiram pôr em evidência: importantes variaçốes espaciais (verticais e laterais) na estrutura interna das aluviôes, com claras consequências na heterogeneidade hidrogeológica do meio aquífero; a ocorrência de uma família de fracturação $\mathrm{N} 8^{\circ} \mathrm{E}$ que retalha o soco paleozoico em blocos com movimentação vertical. Admite-se que a complexidade estrutural e morfológica das formaçóes do soco tenha condicionado a deposiçáo sedimentar e promovido a heterogeneidade estrutural e hidrogeológica das aluvióes.

Palavras-chave - Geofísica; métodos eléctricos; aluvião; aquífero; hidrogeologia; heterogeneidade

Abstract - The alluvial deposit of Vila Nova, Penacova (Central Portugal) is located on the left bank of the Mondego River and has a major length slightly greater than $1 \mathrm{~km}$

\footnotetext{
${ }^{1}$ FCTUC - Universidade de Coimbra, Centro de Geofísica e Depto. de Ciências da Terra; ndaveiga@ci.uc.pt

${ }^{2}$ FCTUC - Universidade de Coimbra, Centro de Geofísica e Depto. de Ciências da Terra; jazevedo@dct.uc.pt
} 
in the NS direction. This region is crossed by the Buçaco-Penedo de Gois syncline, which is oriented NW-SE and composed of Ordovician-Silurian series. The alluvial deposit is bedded on the core rocks of the Paleozoic syncline. Within the deposit formation occurs an unconfined aquifer, which is westward limited by the Mondego River and inferiorly and eastward by the low hydraulic conductivity Paleozoic rocks. Geophysical surveys were conducted over this alluvial deposit. They led to the acquisition of electrical resistivity two-dimensional sections, which put in evidence: (1) an important spatial (vertical and lateral) variation in the internal structure of the alluvial deposit, with clear consequences in the hydrogeological heterogeneity of the aquifer medium; (2) the occurrence of a $N 8^{\circ} \mathrm{E}$ fracture family, delimiting blocks of Paleozoic formations with vertical displacement. The structural and morphological complexity of the bedrock formations is viewed as having conditioned the sedimentary deposition and promoted the structural and hydrogeological heterogeneity of the alluvial deposits.

Keywords - Geophysics; electrical methods; alluvium; aquifer; hydrogeology; heterogeneity

\section{1 - Introdução}

Ao longo das margens do Mondego, mesmo nas regióes onde o seu curso é acentuadamente encaixado, como sucede a montante de Coimbra, estáo presentes algumas manchas de depósitos aluvionares, em regra de pequenas dimensóes. Ocorrendo estas manchas num contexto geológico de soco cristalino hercínico, elas assumem uma importância acrescida, entre outros factores devido às características de porosidade e permeabilidade elevadas que poderão apresentar, e que se traduzem numa elevada capacidade de circulação e armazenamento hídricos, podendo constituir reservatórios localmente importantes. Importante ainda é a relação hidrodinâmica permanente com a linha de água adjacente.

Ocasionalmente, alguma destas manchas apresenta uma extensão bastante acima da média, sendo este o caso das aluvióes de Vila Nova, na região de Penacova (Fig. 1). Nestes casos há em regra um enquadramento geológico/estrutural que possibilitou tal ocorrência. 


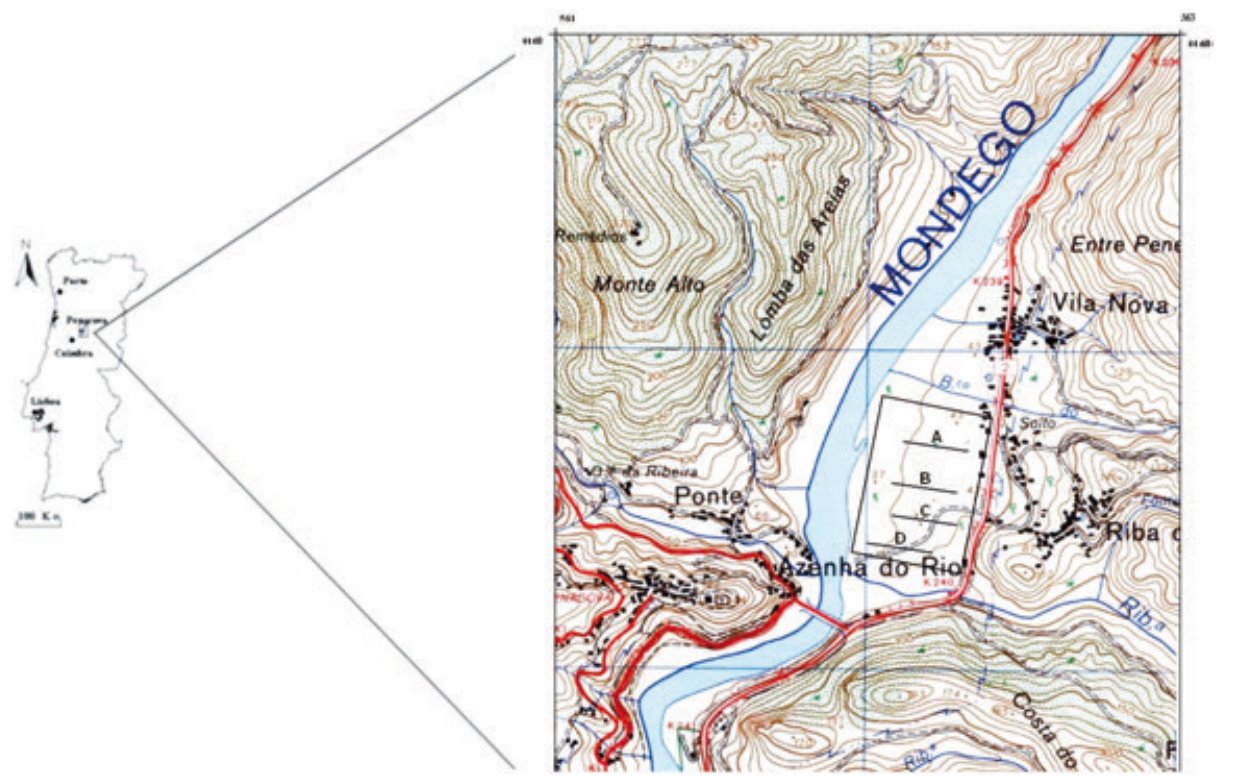

Fig. 1 - Enquadramento da área estudada (excerto da Carta Militar de Portugal, 1:25.000, Folha no 231).

Com indicação da sequência dos perfis e da sua orientaçâo (A, B, C e D).

Do ponto de vista da abordagem hidrogeológica de um meio poroso deste tipo torna-se, obviamente, da maior relevância o conhecimento da variabilidade espacial das aluvióes, quer em termos da sua possança, quer da variabilidade interna em termos litológicos. Assumem maior relevo as variaçóes granulométricas dos sedimentos, bem como a presença e a geometria de níveis argilosos.

Neste contexto, os levantamentos efetuados na região de Penacova com métodos geofísicos eléctricos permitiram, de facto, pôr em evidência variaçóes laterais e verticais nos depósitos aluvionares. E permitiram ainda estabelecer ligações entre a sua estruturação e o soco subjacente.

\section{2 - Enquadramento geológico e hidrogeológico}

A regiāo de Penacova situa-se nas proximidades de Coimbra, a cerca de $20 \mathrm{~km}$ para montante, ao longo do Mondego. Os depósitos aluvionares de Vila Nova formam uma mancha na margem esquerda do rio (Fig. 1), praticamente em frente de Penacova.

$\mathrm{Na}$ zona de Penacova conjugam-se factores de ordem geológica que conferem à regiâo características peculiares. A região é atravessada pelo sinclinal Ordovícico-Silúrico do Buçaco-Penedo de Góis, com orientação NW-SE, cujas formaçôes assentam em discordância sobre os xistos argilosos e metagrauvaques do "Complexo Xisto-Grauváquico" (Pré-Câmbrico terminal a Câmbrico inferior). Neste sinclinal estão presentes: grauvaques vermelhos de base (Ordovícico inferior), quartzitos com raras intercalaçóes pelíticas (Ordovícico inferior-médio), uma série xistenta e psamítica com intercalaçôes quartzíticas 
(Ordovício médio-superior) e xistos nodulares do Silúrico (COSTA, 1950; RIBEIRO et al., 1980; TEIXEIRA, 1981). Por outro lado, este mesmo sinclinal é cortado pela falha Verin-Penacova, com orientação NNE-SSW. A região foi sujeita a intensa deformação desde o Devónico médio, apresentando uma rede de fracturação densa e muito penetrativa (SEQUEIRA et al., 1997). Ainda de acordo com estes autores, terá havido reativação desta fracturação, em particular nos últimos $10 \mathrm{Ma}$.

Verifica-se que a passagem do rio Mondego, junto à vila de Penacova, é fortemente condicionada pela fracturação, que é aproveitada pelo rio para definir o seu traçado. Em relação com este contexto surgem localmente manchas aluvionares, presentes apenas nalguns troços das margens do Mondego, situando-se a alguns metros acima do nível de deposição atual. Os materiais constituintes são essencialmente terrígenos, de granulometria grosseira, por vezes mista (fina-grosseira) ou com intercalaçóes de material fino, sobretudo de natureza limosa.

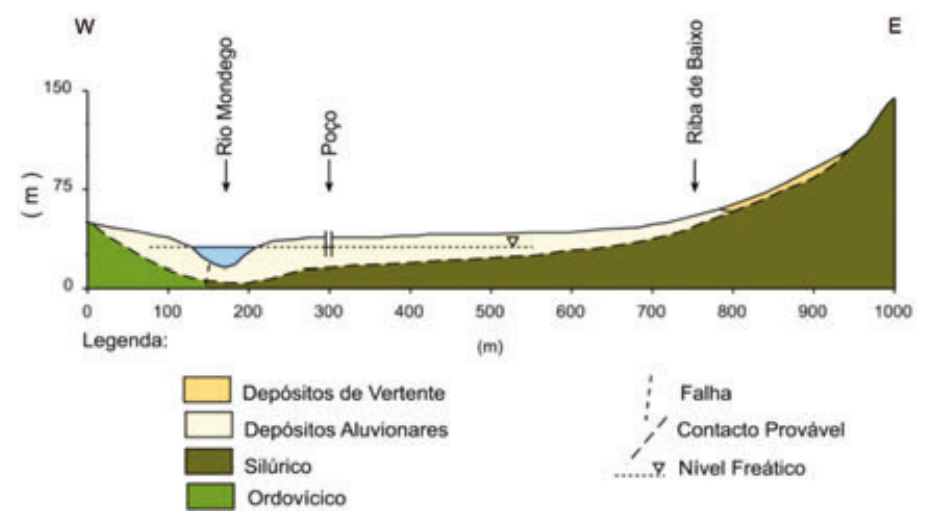

Figura 2 - Perfil geológico esquemático da região em estudo (AZEVEDO \& SILVA, 2004).

O depósito aluvionar estudado corresponde à mancha de maiores dimensôes na região. Este depósito assentará sobre as séries do núcleo do sinclinal Ordovícico-Silúrico. Forma uma mancha com uma extensão superior a $1 \mathrm{~km}$ segundo uma direçáo NNE-SSW e largura inferior a 0,4 km, que evolui na margem esquerda do rio Mondego, junto à povoação de Vila Nova; estende-se desde o leito do rio até cotas próximas dos 50 m (Fig. 2).

Nas formações aluvionares desenvolve-se um aquífero não-confinado. Encontra-se limitado a W pelo Rio Mondego; inferiormente e a E contacta com as formaçóes pró-impermeáveis do sinclinal Ordovícico-Silúrico.

Os domínios grosseiros do meio aquífero poroso apresentam porosidade elevada ( $n=20$ a $30 \%)$ e uma considerável condutividade hidráulica média $\left(K=10^{-4}\right.$ a $\left.10^{-2} \mathrm{~m} \cdot \mathrm{s}^{-1}\right)$ (AZEVEDO \& SILVA, 2004).

A hidrodinâmica intra-aquífera é claramente condicionada pela relação com o rio Mondego e apresenta variaçóes sazonais (AZEVEDO \& SILVA, 2004). A carta piezométrica efetuada em período invernal (Fig. 3) aponta para uma circulaçáo subterrânea complexa, possivelmente associada à presença de várias unidades aquíferas de reduzida dimensão com interligaçóes hidráulicas. 


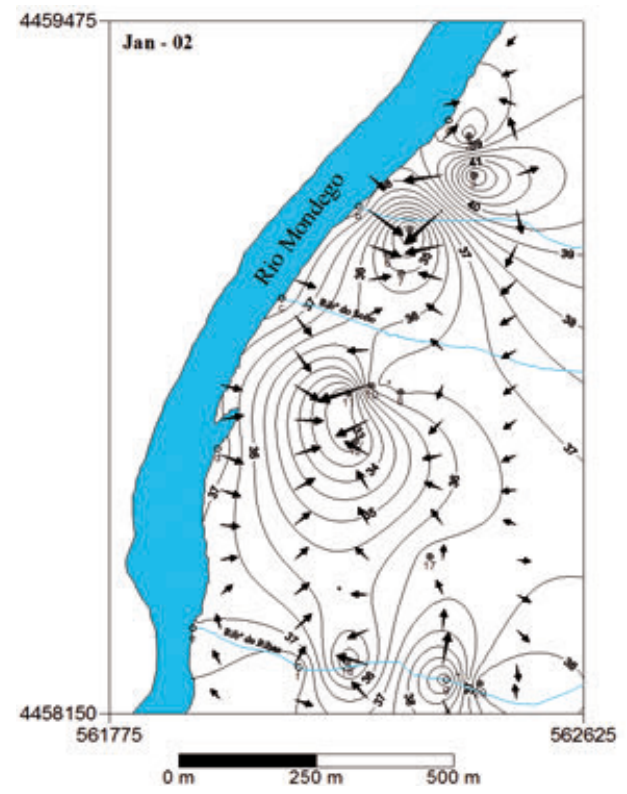

Figura 3 - Carta piezométrica do aquífero aluvionar não-confinado de Vila Nova, Penacova (AZEVEDO \& SILVA, 2004).

A recarga aquífera decorre da precipitação atmosférica e da infiltração associada. A ligação hidrodinâmica com o rio Mondego contribui igualmente para este processo, assim como a descarga invernal a partir da ribeira de Ribas.

A descarga aquífera efetua-se por processos naturais, nomeadamente através de exsurgências e da ligaçáo hidrodinâmica com o rio Mondego e ribeiras afluentes. A captação hídrica nos poços locais constitui um processo de descarga induzida.

\section{3 - Levantamentos com métodos geofísicos}

\section{1 - Metodologia}

Os trabalhos de campo compreenderam a realização de levantamentos com métodos eléctricos. Foi utilizado um resistivímetro IRIS Syscal Jr., tendo sido efetuadas mediçôes com eléctrodos múltiplos. As medições foram realizadas com um dispositivo base Wenner-Schlumberger; em cada perfil foram repetidas usando um dispositivo dipolo-dipolo. Tal permite fazer uma comparação de resultados. O espaçamento entre eléctrodos foi de $5 \mathrm{~m}$. Como tal atingiram-se profundidades de investigação que foram para além da base das aluvióes, tendo sido possível pôr em evidência variaçôes ao nível do soco. Os perfis foram executados perpendicularmente ao alongamento da mancha aluvionar, com uma orientação próximo de E-W. As secções $2 \mathrm{D}$ obtidas foram processadas com o programa Res2Dinv. 


\section{2 - Resultados obtidos}

Os resultados obtidos estão condensados nas secções de resistividade eléctrica mostradas nas figuras 4 e 5 . Nestas secções, as profundidades representadas são da ordem dos 30-35 m no caso dos perfis Wenner-Schlumberger da Fig. 4; e de 25 m no caso dos perfis dipolo-dipolo representados na Fig. 5. É patente, nestas secções, a existência de uma variabilidade acentuada na distribuição espacial dos valores de resistividade eléctrica do terreno, o que traduz a existência de um meio acentuadamente heterogéneo, com variaçóes laterais e verticais nos corpos geológicos na zona em causa.

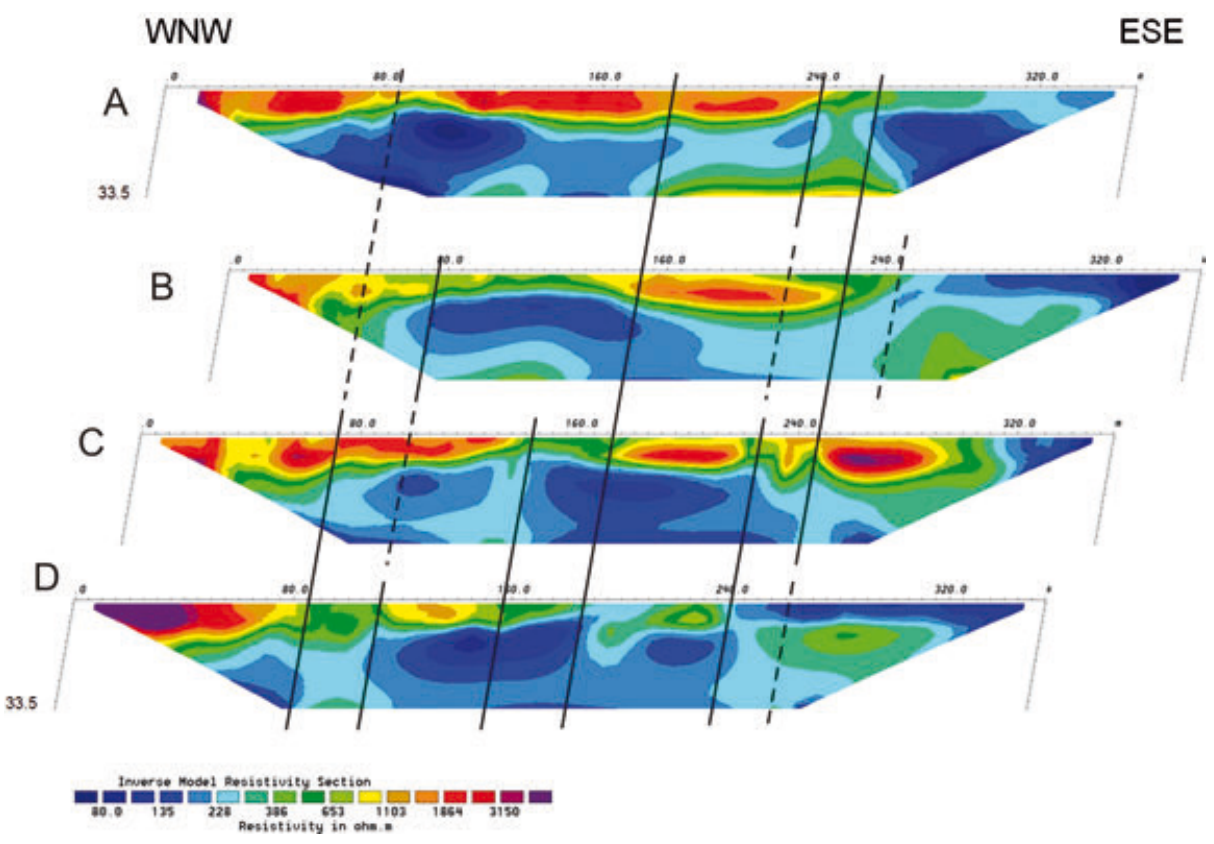

Fig. 4 - Secçốes de resistividade obtidas com um dispositivo Wenner-Schlumberger. Distâncias e profundidades em metros.

As rochas de tipo detrítico, com porosidade intergranular e fraca cimentação, apresentam no geral uma boa correlação (positiva) entre os valores de resistividade da rocha e a granulometria da mesma (tal como se pode encontrar, por exemplo, em MEYER DE STADELHOFEN, 1991). Assim é que depósitos grosseiros, conglomeráticos ou de cascalho e areão, tendem a apresentar valores de resistividade mais elevados que depósitos constituídos por areias mais finas. A presença de argila também tende a baixar a resistividade dos corpos litológicos onde ela ocorre. Deste modo, torna-se possível fazer uma interpretação das secçôes de resistividade em termos de variaçóes da litologia/granulometria dos depósitos. Sendo as diferenças de cota reduzidas, ao longo de cada perfil, não é de esperar que variaçóes laterais de resistividade eléctrica relativamente acentuadas estejam relacionadas com variaçóes pronunciadas no grau de saturação das unidades presentes. 
Os terrenos de origem aluvionar terão espessuras médias da ordem dos 7 a $10 \mathrm{~m}$. Esta espessura tende a ser superior a oeste, junto ao rio. Na Fig. 4, na secção inferior (D), os depósitos mais finos encontram-se na zona oriental do perfil, com resistividades inferiores a 150 W.m $(240-350 \mathrm{~m})$. Entre os 215-240 $\mathrm{m}$ há um corpo com granulometria mais grosseira. $\mathrm{O}$ mesmo se verifica, com maior continuidade, entre os $0 \mathrm{~m}$ e os 180 $\mathrm{m}$, sendo que se observa uma tendência para um aumento da espessura dos depósitos dos $180 \mathrm{~m}$ para os $0 \mathrm{~m}$. Na zona mais próxima do rio, a oeste, conjuntamente com um aumento da espessura, os depósitos têm resistividades elevadas, superiores a 1500-2000 W.m. Nesta zona, mais próxima do rio, as cotas são mais baixas do que para Este, pelo que este facto náo pode explicar o aumento da resistividade dos materiais aluvionares. Tal tem a ver com a presença de depósitos muito grosseiros, conglomeráticos, o que de resto é observável localmente no terreno.

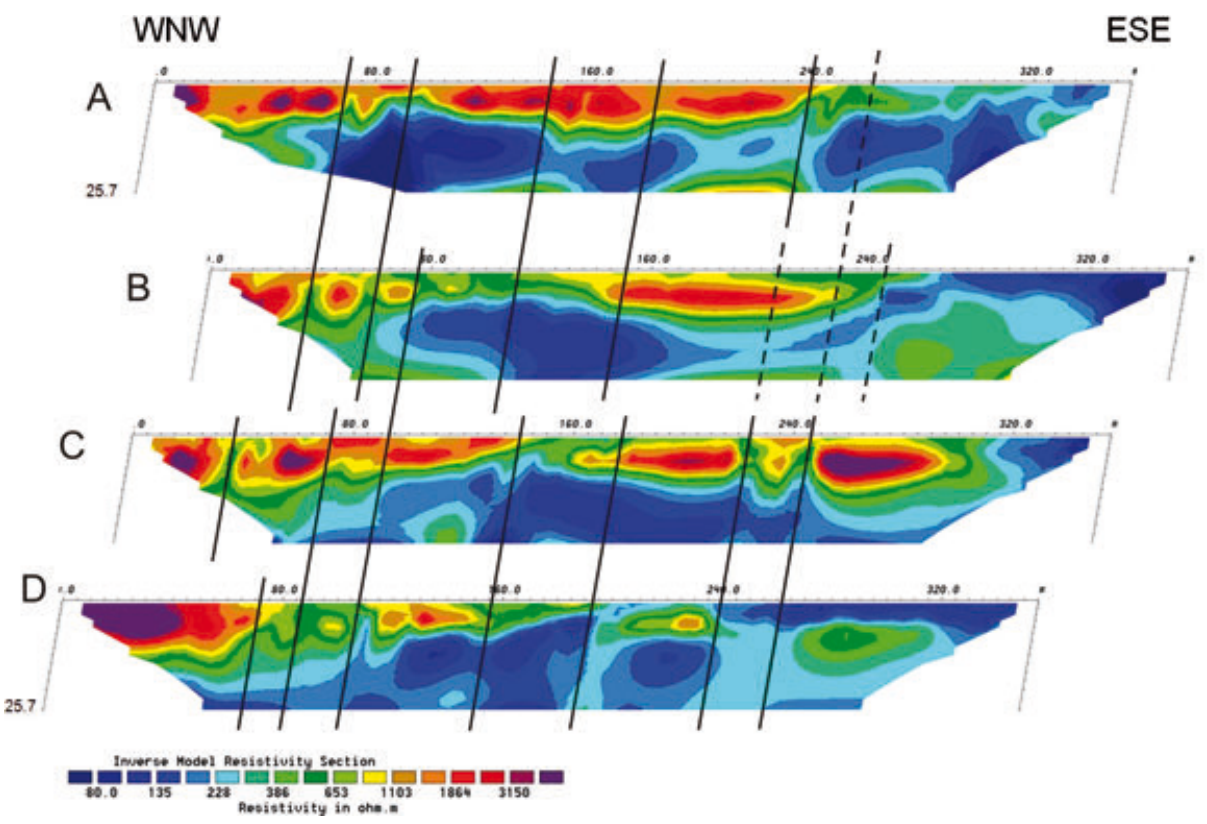

Fig. 5 - Secções de resistividade obtidas com um dispositivo dipolo-dipolo. Distâncias e profundidades em metros.

Além de variaçôes laterais nos depósitos, são observáveis variaçôes verticais. Estas são mais evidentes nas secçôes correspondentes às mediçôes feitas com um dispositivo dipolo-dipolo, representadas na Fig. 5. Nestas secçóes, nota-se com frequência a presença de um nível superior com espessura relativamente reduzida e resistividade mais baixa, que se sobrepóe a depósitos mais grosseiros evidenciando uma resistividade mais elevada. Tal é visível no perfil C da Fig. 5 aos 180-215 m e aos 250-280 m, por exemplo; mas o mesmo se repete noutros perfis. Neste perfil C também é observável o oposto, aos $80 \mathrm{~m}$, havendo aqui depósitos mais grosseiros que se sobreporão a depósitos mais finos.

Para além da variabilidade lateral e vertical nas aluviōes, as secçóes de resistividade eléctrica das Figs. 4 e 5 póem em evidência a existência de variaçóes laterais ao nível do próprio soco. Observando novamente a secção inferior (secção D) da Fig. 4, aos 240 m, 
a uma descontinuidade lateral na resistividade das aluvióes (superior a Oeste; inferior a Este) corresponde uma outra descontinuidade ao nível do substrato paleozoico, mas desta vez de sentido inverso (inferior a Oeste; superior a Este). Esta variação no soco, a existir sozinha, poderia ser associada a uma variação litológica de séries verticalizadas. A variação simultânea ao nível do soco e da cobertura aponta claramente para um controlo por falha.

A análise conjunta dos diferentes perfis das Figs. 4 e 5 mostra a existência de padrōes que se podem seguir de perfil para perfil e que permitem traçar as falhas entre as secções. Desta forma, as falhas marcadas aos $240 \mathrm{~m}$ e $260 \mathrm{~m}$ na secção D podem-se seguir na secção $\mathrm{C}$ e até à $\mathrm{A}$, havendo contudo, entre perfis, algumas variaçóes no padrão base. Nos perfis D, C e A as aluvióes apresentam resistividades mais baixas a Este e mais elevadas a Oeste. É notório, nestes perfis, que as falhas aos $240 \mathrm{~m} / 260 \mathrm{~m}$ criam as condiçôes para a implantaçáo de depósitos mais grosseiros do que os existentes na zona mais oriental, depósitos estes que vão encostar neste alinhamento de falha com orientaçáo $\mathrm{N} 8^{\circ} \mathrm{E}$. Estas falhas e estes depósitos marcam-se igualmente no perfil C, mas a existência de uma lentícula com resistividade elevada para Este do alinhamento das falhas introduz uma diferença no padrão de variação ao nível dos depósitos aluvionares.

Ao nível do substrato Paleozoico, a resistividade é mais elevada a Este das falhas sitas aos $240 \mathrm{~m} / 260 \mathrm{~m}$ do que a Oeste (perfis D, C e B), com valores da ordem dos 500 W.m no primeiro caso e inferiores a $200 \mathrm{~W} . \mathrm{m}$ no segundo. Este contraste de valores poderá estar relacionado com uma variaçáo litológica associada a um rejecto na dependência das falhas mencionadas, ou à fracturação e esmagamento de uma rocha original xistenta; ou, eventualmente, a ambos os mecanismos. No perfil B, contudo, tanto este padrão, observável ao nível do soco, como o limite dos depósitos aluvionares com resistividade elevada mostram um desvio de cerca de $20 \mathrm{~m}$ para Este, parecendo indicar algumas variaçóes no controlo por cada uma das falhas paralelas aos $240 \mathrm{~m} / 260 \mathrm{~m}$. No perfil A a situação é distinta: neste caso, ao invés dos outros perfis, ao nível do soco, é o bloco a Este das falhas que apresenta resistividades tendencialmente mais baixas que a Oeste. Tal aponta para a existência de outro factor de estruturaçáo ao nível do soco, litológico ou estrutural, com uma orientação diferente das já apontadas.

Outras falhas há cuja influência se faz sentir simultaneamente ao nível do soco e da cobertura aluvionar, mais evidentes nomeadamente aos $110 \mathrm{~m}$ e aos $190 \mathrm{~m}$ na secção D das Figs. 4 e 5; e aos 95 m e 145 m na secção C, podendo apontar-se outros casos. Na zona mais perto do rio, a Oeste, é notório, em todos os perfis, a existência de um condicionamento por uma família de falhas que se traduz num progressivo aumento da espessura das aluvióes para Oeste.

A heterogeneidade na composiçáo e estruturaçáo das aluviōes traduz-se, naturalmente, numa heterogeneidade das características hidrogeológicas das mesmas. Tal parece ser acentuado pelo controlo exercido pela fracturação na implantação dos depósitos aluvionares.

\section{4 - Conclusão}

Os levantamentos com métodos geofísicos eléctricos permitiram pôr em evidência: (1) a existência de acentuadas variaçóes laterais e verticais nas aluviōes de Vila Nova; (2) a ocorrência de uma família de fracturas com orientação $\mathrm{N} 8^{\circ} \mathrm{E}$ ao nível do soco paleozoico; (3) a relaçẫo entre a fracturação do soco e as variações na estrutura interna dos depósitos aluvionares. 
Assim, admite-se que a complexidade estrutural e morfológica das formaçóes do soco tenha condicionado a deposiçáo sedimentar e promovido a heterogeneidade estrutural e hidrogeológica das aluviôes.

\section{Referências Bibliográficas}

AZEVEDO, J.M.M. \& SILVA, S.M.R. (2004) - Hidrogeologia e importância ambiental de pequenos aquíferos associados a depósitos aluvionares: o exemplo do aquífero de Vila Nova, Penacova. - Anais da $8^{a}$ Conferência Nacional de Ambiente. Univ. Nova Lisboa, 7p.

COSTA, J. C. (1950) - Notícia sobre uma Carta Geológica do Buçaco de Nery Delgado. - Publicaçóes dos Serviços Geológicos de Portugal, Lisboa, 27p.

MEYER DE STADELHOFEN, C. (1991) - Applications de la géophysique aux recherches d'eau. Lavoisier, Paris.

RIBEIRO, A.; ANTUNES, M. T.; FERREIRA, P.; ROCHA, R. B.; FERREIRA SOARES, A.; ZBYSZEWSKY, G.; ALMEIDA, F. M.; CARVALHO, D. \& MONTEIRO, J. (1980) - Introduction à la géologie générale du Portugal. Serviços Geológicos de Portugal, Lisboa, 114 pp.

SEQUEIRA, A. J. D., CUNHA, P. P. \& SOUSA, M. B. (1997) - A reactivação de falhas, no intenso contexto compressivo desde meados do Tortoniano, na região de Espinhal-Coja-Caramulo (Portugal Central). - Comunicaçöes do Instituto Geológico e Mineiro, Tomo 83, p. 95-126.

TEIXEIRA, C. (1981) - Geologia de Portugal, Vol. I, Pré-Câmbrico e Paleozóico. Fundação Calouste Gulbenkian, Lisboa, p. 69-72. 